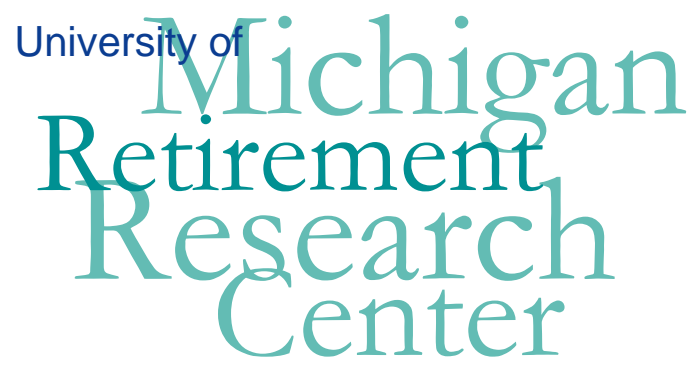

Working Paper

WP 2007-163

\begin{abstract}
Take-Up of Medicare Part D and the SSA Subsidy: Early Results from the Health and Retirement Study
\end{abstract}

Helen Levy and David R. Weir

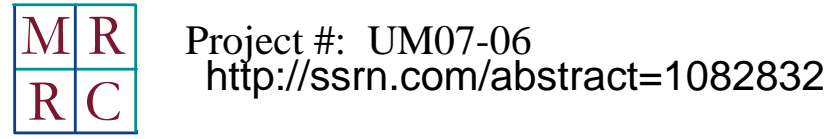




\title{
Take-Up of Medicare Part D and the SSA Subsidy: Early Results from the Health and Retirement Study
}

\author{
Helen Levy \\ University of Michigan \\ David R. Weir \\ University of Michigan
}

October 2007

\author{
Michigan Retirement Research Center \\ University of Michigan \\ P.O. Box 1248 \\ Ann Arbor, MI 48104 \\ http://www.mrrc.isr.umich.edu/
}

(734) 615-0422

\section{Acknowledgements}

This work was supported by a grant from the Social Security Administration through the Michigan Retirement Research Center (Grant \# 10-P-98362-5-04). The findings and conclusions expressed are solely those of the author and do not represent the views of the Social Security Administration, any agency of the Federal government, or the Michigan Retirement Research Center.

\section{Regents of the University of Michigan}

Julia Donovan Darrow, Ann Arbor; Laurence B. Deitch, Bingham Farms; Olivia P. Maynard, Goodrich; Rebecca McGowan, Ann Arbor; Andrea Fischer Newman, Ann Arbor; Andrew C. Richner, Grosse Pointe Park; S. Martin Taylor, Gross Pointe Farms; Katherine E. White, Ann Arbor; Mary Sue Coleman, ex officio 


\title{
Take-Up of Medicare Part D and the SSA Subsidy: Early Results from the Health and Retirement Study
}

\author{
Helen Levy and David R. Weir
}

\begin{abstract}
We analyze newly available data from the Health and Retirement Study on senior citizens' take-up of Medicare Part D and the associated SSA Low-Income Subsidy. We find that economic factors - specifically, demand for prescription drugs - drove the decision to enroll in Part D. For the most part, individuals with employer-sponsored coverage in 2004 kept that coverage, as they should have. Individuals with no prescription drug coverage in 2004 mostly enrolled in Part D or obtained other coverage; many of those who remained without coverage reported that they do not use prescribed medicines. Take-up of the SSA "Extra Help" subsidy seems to have been more problematic, with many Part D beneficiaries unaware of the subsidy program or unsure about their eligibility. There is apparent under-reporting in the HRS of participation in the subsidy program, suggesting that some who profess to be unaware of the program may actually be participating in it. In terms of respondents' subjective experiences of decision-making, the majority report having had little or no difficulty with the Part D enrollment decision and being confident that they made the right decision. Thus, for the most part, despite the complexity of the program, Medicare beneficiaries seem to have been able to make economically rational decisions in which they had confidence, although additional intervention for low-income beneficiaries may be desirable.
\end{abstract}

\section{Authors' Acknowledgements}

The research reported herein was pursuant to a grant from the U.S. Social Security Administration (SSA) funded as part of the Retirement Research Consortium (RRC). The findings and conclusions expressed are solely those of the authors and do not represent the views of SSA, any agency of the Federal Government or the RRC. This analysis uses Early Release data from the 2006 wave of the Health and Retirement Study, sponsored by the National Institute of Aging (NIA U01AG009740) with additional support from SSA. Joanna DeBartolo provided excellent research assistance. 


\section{Introduction}

The new Medicare prescription drug benefit, commonly referred to as "Part D," began in January 2006. Unlike Medicare Parts A and B, takeup of which is close to universal among eligible individuals as a result of essentially automatic enrollment, Part $\mathrm{D}$ requires most beneficiaries to make an active choice about whether or not to participate. Beneficiaries who want to enroll in Part D must choose a prescription drug insurance plan and, in most cases, pay a separate premium for this coverage. Lowincome beneficiaries are also eligible for a subsidy to help cover the Part D premium, deductible and copayments, but this subsidy requires an application that is separate from Part D enrollment. Part D and the accompanying low-income subsidy therefore required most eligible beneficiaries to make a series of active decisions in order to take up benefits.

How successfully did elderly Medicare beneficiaries navigate the complex set of choices presented by Part D? In particular, we are interested in whether beneficiaries took up benefits that were available to them. Understanding takeup is interesting for at least three reasons. First, we want to know whether these benefits are reaching the individuals they are intended to help. Second, low rates of takeup may suggest costs of enrolling that reduce the value of the program even for those who enroll. In the words of Blundell et al. (1988): "the existence of non-take-up also suggests that there are costs associated with claiming, which not only deter non-claimants but also partly offset the value of benefits to those who do claim." Third, the underlying "managed competition" framework of the Part D program, in which individuals choose private insurance plans in a regulated and subsidized market, forms the basis for many proposals to expand health insurance coverage in the under-65 population as well. ${ }^{1}$ The primary alternative framework for policies to expand coverage is one in which government functions as insurer, like Part A of the Medicare program. The success or failure of Part D becomes, in effect, an important test case for the potential of market-based reforms relying on private plans and individual choices to expand insurance coverage.

\footnotetext{
${ }^{1}$ For example, the Clinton health care plan in the early 1990s and the health care reform proposals of current Democratic candidates John Edwards and Barack Obama are all built on a framework of managed competition.
} 
A priori, there is considerable reason to expect low takeup of both Part D and the associated subsidy. Takeup of most social benefits is low (for a review, see Currie 2004). Moreoever, the tasks required of prospective Part D enrollees - who in most cases had to decide not only whether to take up the program but also had to choose a plan from a menu of complicated options - are considerably more complex than deciding whether or not take up programs like SSI or Food Stamps. Medicare beneficiares may be particularly ill-suited to tackle these complex decisions because many of them have aging-related cognitive limitations. The difficulties associated with the introduction of Medicare HMOs in 1997, which were initially unpopular with enrollees, is a discouraging example of how such a scenario might play out.

In this paper, we present evidence from the Health and Retirement Study (HRS) which suggests that in spite of all of these challenges, takeup of Part D among elderly Medicare beneficiaries was relatively high, and that most beneficiaries made good decisions about which they felt confident. Only 7 percent of all seniors lack drug coverage in 2006 compared with 23 percent in 2004.Focusing on the relatively small group of eligible individuals who chose to go without coverage, there is very little evidence to suggest that substantial numbers of them were confused or misinformed; rather, they appear to have low demand for prescription drugs, and may have been quite rational in their decision not to sign up for Part D.

Takeup of the subsidy program, on the other hand, seems to have been low even compared with the low rates of takeup for other social programs. Here, lack of information seems to have been a factor. Many respondents reported that they did not apply because they had not heard of the program and many more gave responses suggesting that they were confused about the subsidy. Although running the subsidy application process through SSA may have reduced stigma, and was administratively simpler because in most cases Part $\mathrm{D}$ premiums were paid by deduction from Social Security payments, it may have added to the cognitive demands.

Despite the apparent low take-up of the low-income subsidy, there is no apparent difference in Part D coverage between the subsidy-eligible and other groups, even when Medicaid recipients are set aside. That is, the fraction of seniors who have no drug coverage is about the same at all income levels. Thus, it appears that low-income groups 
did navigate the program and are receiving the benefits of the heavily subsidized insurance of Part D, but are not fully benefiting from the extra help available to them.

The paper proceeds as follows. The next section describes the relevant institutional features of the Part D benefit and the associated low-income subsidy. Section 3 discusses the literature on economic models of program takeup. Section 4 discusses the HRS data available for evaluating takeup of Part D and the subsidy and how we define key variables for our analysis. Section 5 presents descriptive and multivariate results, and Section 6 concludes with a discussion of the implications of our results.

\section{Background on Part D and the Low-Income Subsidy}

The Medicare Modernization Act of 2003 established the prescription drug benefit known as "Part D," which is administered by the Center for Medicare and Medicaid Services (CMS). In addition, the Act also established a means-tested subsidy to help cover premiums, deductibles and copayments for beneficiaries with low incomes and few assets. The application and approval process for the low-income subsidy (referred to as "extra help" in the public information campaign) is handled by SSA. The Congressional Budget Office estimated that about 1/3 of Medicare beneficiaries would qualify for the means-tested subsidy, which, if used, would represent about a $20 \%$ increase in income for those at the poverty level (CBO, 2004)

Medicare beneficiaries were affected very differently by Part D and the subsidy depending on what their prior prescription drug insurance was.

- Individuals with "other creditable coverage" - that is, insurance coverage with actuarial value greater than or equal to the standard Part D plan - were instructed to keep that coverage. This was, for the most part, employersponsored group coverage, and those employers received a subsidy from the government to continue offering it.

- Medicaid-covered Medicare beneficiaries (“dual eligibles”) were automatically enrolled in both Part D and the subsidy.

- Medicare Advantage plans (HMOs), many of which were already providing drug coverage prior to 2006, essentially had to offer drug coverage under Part D, so that Medicare HMO enrollees were more or less assured of participating 
in Part D. ${ }^{2}$ Medicare HMO enrollees interested in applying for the subsidy had to make a separate application to SSA including information on income and assets.

- Individuals with privately purchased prescription drug insurance or with no coverage for prescription drugs had to decide whether they wanted to enroll in Part $\mathrm{D}$ and if so choose a plan and sign up for it. ${ }^{3}$ They also had the option of enrolling in a Medicare Advantage plan-many of which were marketed by the same companies as stand-alone Part D plans. If they wanted to apply for the subsidy they had to make a separate application including information on income and assets to SSA.

In effect, then, individuals with privately purchased drug coverage and individuals with no drug coverage had to decide whether or not to sign up for Part D and whether or not to apply for the subsidy; Medicare HMO enrollees had to decide only whether or not to apply for the subsidy. Individuals with employer-sponsored coverage had no decisions to make. Medicaid/Medicare dual eligibles could either do nothing and be automatically enrolled in both a Part D plan and the subsidy, or they could actively choose a plan and switch into it from the one to which they had been automatically assigned.

Eligibility for the subsidy is based on beneficiaries' income and assets. Individuals with incomes below 135 percent of the poverty level and assets below $\$ 6,000$ for singles or $\$ 10,000$ for couples were eligible for a full subsidy in 2006. A partial subsidy was available for individuals with incomes up to 150 percent of the poverty level and assets below $\$ 9,000$ for singles or $\$ 20,000$ for couples. The definition of income used for eligibility differs from that used to calculate poverty levels because it excludes some types of income. Specifically, the income of other household members is not counted, and the poverty thresholds for one and two-person households apply for single and married individuals. In addition, the first $\$ 240$ of annual income is disregarded; the first $\$ 720$ of annual earnings and half of all earnings above that level is also disregarded.

\footnotetext{
${ }^{2}$ Enrollees in Medicare HMOs could not enroll in a stand-alone Part D plan without losing their Medicare HMO benefits for outpatient and inpatient care, so that in effect Medicare HMOs not already providing drug coverage would have lost most of their enrollees if they had not started to provide it. Of course, ${ }^{3}$ Medigap plans that included prescription drug coverage prior to 2006 could continue to sell that product to existing enrollees but could not enroll new members. Presumably, any Medigap plan that included drug coverage became a Part D plan.
} 
Assets include all liquid assets; a beneficiary's primary residence and vehicles are not counted. As a result, the rates of eligibility for at least partial subsidy are considerably higher than poverty rates.

Prior estimates of eligibility for the subsidy suggest that 13.2 million people, approximately one-third of all Medicare beneficiaries meet the income and asset tests, and of these roughly 7.6 million would not need to apply for it because they were “deemed” eligible and automatically enrolled (Medicaid recipients and a few others), or had other coverage. That means that 6.6 million, or about $15 \%$ of the Medicare population were potentially eligible but would need to apply.

Both SSA and CMS advertised the subsidy program heavily. According to the Government Accountability Office in testimony before Senate Finance Committee in May of 2007 (GAO-07-858T), SSA held over 75,000 local events, mailed information letters to 18 million Medicare beneficiaries thought to be potentially eligible, and through a contractor made followup telephone calls to 9 million people. The main period of effort was May to November of 2005, prior to the start of Part D coverage. By the end of 2005, 4 million people had applied for the subsidy, and 1 million had been approved. Of the 6.2 million applications received by March of 2007, 2.2 million had been approved, 2.6 million refused, and 1.4 million judged as duplicates or unnecessary because the applicant was already in the program or covered by Medicaid.

\section{Economic models of program take-up.}

Moffitt (1983) is considered the starting point of modern economic models of program take-up. He used a simple utility-maximizing framework to incorporate both the magnitude of potential benefits and the costs of enrollment and participation. He focused in particular on "stigma"-psychic costs associated with means-tested welfare programs. Subsequent research has found pure stigma effects to be relatively unimportant, while transactions costs—-the time spent navigating the system—can be quite significant (see Currie, 2004 for a review of the take-up literature). A priori, since Medicare Parts A and $B$ have near-universal take-up, we would not expect much stigma to be associated with taking up the new benefits under Part D. Given the complexity of the program, transaction costs might be quite significant for Part D. 
Most of the programs considered in the takeup literature have no direct financial cost to the user, so the only costs of taking up the program are stigma or transaction costs. Part $\mathrm{D}$ is different in that it also has a direct financial cost: the premium the beneficiary must pay. For some fraction of the eligible population, the premium exceeds the individual's expected benefit from the program, so that individuals may quite reasonably decide not to participate. In particular, individuals with low expected total prescription drug spending should not take up the plan because they would pay more in premiums than they would get in benefits. Winter et al. (2006a) estimate that the "break-even point" in 2006 is about \$842; that is, individuals with total spending below $\$ 842$ are financially better off not signing up for Part D. They estimate that about 27 percent of the Medicare population has spending below this level. This estimate does not take into account the option value created by the penalty for signing up for Part D later or the risk premium that risk-averse individuals should be willing to pay even if their expected spending for the year falls somewhat below the break-even amount. Either of these factors should push more individuals into signing up. On the other hand, it also does not take into account any stigma or transaction costs, which would discourage people from signing up. These factors work in opposite directions and it is impossible to estimate any of their magnitudes at the individual level. The take-home point, though, is that for a sizeable chunk of the Medicare population - maybe as much as one-quarter - signing up for Part D may not be a good deal.

The Low-Income Subsidy (LIS), on the other hand, has no direct costs and is means-tested, so that takeup of the subsidy is more like takeup of other welfare programs where stigma, transaction costs and lack of information are the leading candidates to explain low takeup. The administration clearly intended to encourage applications for the subsidy, as evidenced by the following quotation from the CMS webpage about the program:

Remember, as Department of Health and Human Services Secretary Leavitt says, "If in doubt, fill it out!"

Nonetheless, existing research suggests that the elderly take up other means-tested social programs at particularly low rates; see, for example analyses of Food Stamps by Haider et al. (2003), of Medicaid by (Pezzin and Kasper (2000), and of SSI by McGarry (1995) 
and by Elder and Powers (2004, 2006). These results suggest that takeup of the LowIncome Subsidy is likely to be low.

\section{Data.}

The Health and Retirement Study (HRS) is the best resource available for longitudinal studies of health and economic well-being. The original HRS cohort, born 1931-41 and first interviewed in 1992 at the ages of 51-61, was interviewed again for the eighth time in 2006, at the ages of 65-75. Thus, all age-eligible members of that cohort are now age-eligible for Medicare. With the other cohorts added after 1992, the HRS now represents the full population of Medicare beneficiaries over age 65. In all, our sample includes 10,175 Medicare-covered individuals ages 65 and older in 2006 who were also present in $2004 .^{4}$

\section{A. Defining respondents' prescription drug insurance coverage}

In the 2004 HRS, respondents had as many as three opportunities to provide information about insurance coverage for prescribed medicines:

- Respondents with Medicare or Medicaid insurance coverage are asked if they get these benefits through an HMO. If they do, they are asked whether the Medicare/Medicaid HMO covers prescription drugs (and other questions about that HMO).

- For up to three private insurance plans, respondents report the source of coverage (own employer, spouse’s employer, privately purchased, etc.) and whether or not the plan covers prescription drugs.

- In the section on utilization of medical care, all respondents are asked whether they regularly take any prescription medications. If they do, they are asked "Have the costs of your prescription medications been completely covered by health insurance, mostly covered, only partially covered, or not covered at all by insurance?” Respondents who do not regularly take any prescription drugs are asked whether they have insurance coverage that would cover the cost of drugs if they took any. All

\footnotetext{
${ }^{4}$ In 2006, the HRS has 11,355 respondents ages 65 and older and 7,116 under 65. Of the respondents ages 65 and older, 415 say they do not have Medicare coverage and another 765 have no data from 2004; after discarding these observations, we have a usable sample of 10,175 respondents ages 65 and older with Medicare in 2006 who were also present in the HRS in 2004.
} 
respondents are asked to provide the name of the plan that covers or would cover prescription drug expenses.

The 2006 HRS includes an additional question to the beginning of the sequence on insurance coverage. Immediately after asking respondents about whether they have Medicare, before any of the questions listed above are asked, respondents are asked "Beginning in 2006, Part D of Medicare provides coverage for prescription drugs. Have you signed up for the new Medicare prescription drug coverage?” Other questions about Part D, including whether or not the person applied for the SSA subsidy, follow.

Based on this information, we assign respondents prescription drug coverage in the following hierarchical order (that is, if a respondent reports more than on of these types of coverage, $\mathrm{s} /$ he is assigned the first one in this list):

\section{Employer coverage (including CHAMPUS/Tricare)}

\section{Medicaid}

\section{Medicare HMO}

4. Part D (2006 only)

5. Privately purchased drug coverage; this category includes both respondents who report having a private non-group insurance policy that covers prescription drugs and respondents who do not report any of the above types of coverage but who report that their prescription drugs are or would be covered by insurance. ${ }^{5}$

6. No coverage is assigned to respondents with none of the above types of coverage.

\section{B. Data on takeup of the low-income subsidy}

In 2006, the HRS asked: "Have you applied to Social Security for extra help in paying for your prescription drugs?" Those who answered yes were then asked "Did you receive any extra help from Social Security?” whereas those who answered no were asked why not. At the beginning of the field period, only persons who said they had signed up for Part D were asked about extra help. This was subsequently changed to ask all Medicare beneficiaries. About one-quarter of Medicare beneficiaries in HRS were not asked about extra help, all of whom said they had not signed up for Part D, but some of whom may have been subsidy-eligible. Appendix table 1 shows how respondents in each

\footnotetext{
${ }^{5}$ In a few cases, we recode responses based on the name of the plan respondents say is covering/would cover their drug expenses (e.g. "Medicaid” and "CHAMPUS” are recoded appropriately).
} 
of the coverage categories we defined responded to questions about Part D and subsidy takeup. In practice, this is not a problem for those with employer coverage or those with Medicaid, whose subsidy status is known based on their insurance coverage. Nor is it a problem for the respondents with stand-alone Part D coverage since, by our definition, they all said yes to the question about Part D and were therefore asked about the subsidy. The main problem is for Medicare HMO enrollees, only about half of whom responded that they had signed up for Part D. As a result, subsidy application data is missing for a quarter of those with Medicare HMO drug coverage. In the analysis that follows, present a range of results for Medicare HMO enrollees using different assumptions about what the missing values mean.

4C. Other variables

Prescription drug use 2004: In the 2004 core survey, respondents are asked whether they take medication to treat high blood pressure, diabetes, heart conditions (AMI, angina, congestive heart failure), stroke, or psychiatric conditions. We use the number of conditions for which medications are taken (0-5) in 2004 as a measure of demand for prescription drugs.

Prescription drug use 2006: In the 2006 core survey, respondents are asked whether they take medication to treat high blood pressure, diabetes, heart conditions (AMI, angina, congestive heart failure), stroke, or psychiatric conditions, and in addition whether they take prescription drugs for pain, allergy/asthma, GI problems, cholesterol, sleep aid, or anxiety/depression. We use the number of conditions for which medications are taken (011) in 2006 as a measure of demand for prescription drugs. This has obvious potential endogeneity problems. However, the fact that Part D offered insurance to everyone actually lessens the endogeneity problems of prior drug use, which was strongly conditioned on the unequal availability of insurance. In work not reported here, we have found that the number of medications reported in late 2005 in a separate mail survey prior to Part D shows results very similar to this.

Subsidy eligibility: Eligibility for the low-income subsidy is based on the rules described above. Using detailed HRS data on 2005 income and assets, which are reported in the 2006 core survey, we are able to follow the eligibility rules quite closely in order to 
construct measures of countable income and assets for purposes of determining eligibility.

Cognition: In the HRS core survey, interviewers read a list of ten words to respondents, who then recall as many words as they can. They are asked to recall the words immediately after hearing the list and also several minutes later. We use the sum of these from the 2006 survey, ranging from 0 to 20, as an indicator of cognitive ability. Many respondents who have difficulty with this task refuse to complete it and have missing data as a result, so we treat missing data as a separate category for this variable.

Health: Respondents report their own health status as excellent, very good, good, fair, poor in every wave of the HRS core. We use data on self-reported health in 2004.

Education: Respondents are classified into four groups based on their reported educational attainment at the baseline interview: less than high school, high school graduate, some college, college graduate or more.

Demographic variables: We also include race (white, black, other nonwhite), ethnicity (Hispanic, non-Hispanic), marital status and age as explanatory variables in our analysis.

\section{Results}

Table 1 shows the distribution of this sample by type of insurance coverage in 2004 and also characteristics for each subgroup. ${ }^{6}$ In 2004, nearly a quarter (23 percent) of the sample had no prescription drug coverage. About a third (34.5 percent) had drug coverage through an employer plan and another 23 percent had coverage through an individually purchased private plan; Medicare HMOs and Medicaid covered another 12 and 7 percent, respectively.

Overall, 28 percent of respondents report that they are in fair or poor health. Twothirds of them take medication to treat one or more of high blood pressure, diabetes, heart conditions (AMI, angina, congestive heart failure), stroke, or psychiatric conditions. ${ }^{7}$ Medicaid recipients are in noticeably worse health than the other groups, with almost 60 percent in fair or poor health and nearly 80 percent using prescription drugs for one of the five conditions listed above. Overall, almost one-third of the sample reports 2005 income

\footnotetext{
${ }^{6}$ All estimates in our analysis, except for those reported as unweighted sample sizes, are weighted using the preliminary 2006 respondent weights.

${ }^{7}$ These are the conditions for which use of prescription drugs was asked in Section C in 2004.
} 
and assets below the subsidy eligibility level for Part D in 2006. Thus, HRS data seems consistent with prior estimates of eligibility rates.

Table 2 shows the distribution of prescription drug insurance coverage in 2006, overall and also by coverage status in 2004. Overall, 25.7 percent of the sample had stand-alone Part D coverage in 2006, 15.1\% had Medicare Advantage plans, and only 7.5 percent had no coverage, compared with 23 percent with no coverage in 2004. These figures are broadly consistent with CMS reports for 2006, which found about 24\% of beneficiaries in stand-alone plans, 13\% in HMOs, and under 10\% with no coverage. Among those who had no coverage in 2004, just over half (52.5 percent) enrolled in a Part D plan in 2006, with another 7.1 percent covered by Medicare HMOs. One-third of individuals who had been purchasing private prescription drug coverage enrolled in Part D plans in 2006, with another 9.6 percent covered by Medicare HMOs. A first estimate of Part D takeup, then, appears to be somewhere between 25 and 50 percent, depending on how it is defined.

Table 3 presents results for the sample categorized according to income and assets relative to eligibility thresholds for the SSA low-income subsidy for Part D. There is surprisingly little variation across these groups in the fraction enrolled in Part D (25 to 30 percent) or the fraction with privately purchased coverage (11 or 12 percent). The main difference across these groups is in the fraction with employer versus Medicaid coverage. Better-off households are much more likely to have employer coverage, which covers 41.5 percent of the richest group compared to only 21.2 percent of subsidy-eligible respondents. Medicaid covers almost as many subsidy-eligible respondents as employer coverage (19.7 percent) but almost none of the richer respondents. These differences by income offset each other so that the fraction with no coverage is about 7 or 8 percent in each group. That is, rich and poor elderly individuals are equally likely to lack prescription drug coverage.

Very few respondents reported that they had applied for the SSA low-income subsidy. Only 13 percent of respondents with stand-alone Part D coverage reported having done so (Table 3), with about half of these reporting that they had gotten the subsidy. Subsidy application rates were about 9 to 10 percent among respondents whom we categorize as close to the eligibility threshold, and were negligible (2 percent) among 
respondents who reported both income and assets high enough to disqualify them from eligibility. Subsidy applications appear to have been slightly less likely from Medicare HMO enrollees but because of the high rate of missing data discussed above we cannot say conclusively how their takeup rate compares to that for beneficiaries in stand-alone Part D plans. Table 4 shows the distribution of outcomes by subsidy eligibility status that these conditional takeup rates imply.

Although precise comparisons will require age-specific administrative data and sampling weights for the HRS 2006 sample, it is clear from these counts that reported applications and receipt of the low-income subsidy in HRS are low relative to published administrative estimates. According to GAO, applications represented about $14 \%$ of the number of Medicare beneficiaries, and the approval rate was about one-third of that, so about 5\% of Medicare beneficiaries have LIS approval. By contrast, only about 3\% of older Medicare beneficiaries in HRS even reported an application. A higher rate, about half, report approval, but the count of approved beneficiaries is still far lower than administrative estimates. This shortfall is much too large to be explained by the change in skip patterns. It must be the case that some people who receive the low-income subsidy nevertheless answered no to the question about applying to Social Security for extra help. One indication that this may be so is the number of people without the subsidy who report paying nothing in premiums. A likely explanation is that people filled out the subsidy application at the same time as they signed up for Part D and did not consider the two to be separate actions but rather all part of Part D. Future work will attempt to identify which of the non-reporters may actually be covered. Ultimately, administrative linkages to SSA and CMS data should permit a definitive answer.

\section{Defining takeup}

Our aim is to study takeup as an economic behavior, i.e., a choice made by a relevant subset of the population. Many different definitions of "takeup" are possible depending on what choice we wish to study and how we define the population at risk for the choice. We might be interested in knowing what fraction of previously uninsured individuals signed up for stand-alone Part D plans, or we might also want to count anyone who enrolled in a Medicare HMO as “taking up" Part D coverage. If we are interested in knowing what fraction of eligible beneficiaries are being reached by this 
program we might want to count Medicaid recipients as well, even though they have no active takeup decision to make since they were automatically enrolled in Part D. Table 5 lists seven possible definitions of Part $\mathrm{D}$ takeup and nine possible definitions of takeup for the "Extra Help" subsidy. The last column of the table shows the sample size in the denominator of the fraction for each takeup calculation. In the multivariate analysis that follows I will present results for all of these outcomes.

Table 6 shows the average takeup, overall and by income/asset category, for each different definition of takeup. Estimates of Part D takeup range from 41 percent using respondent-reported Part D coverage to define takeup to 72.5 percent, counting Part D plans, Medicare HMOs, and Medicaid as Part D and including everyone except individuals with employer coverage in 2006 as "eligible" for being in Part D. Estimates of subsidy takeup (defined as applying to Social Security for extra help) range from 4.4 percent using the respondent-reported measure of subsidy takeup (and keeping in mind the missing data problem discussed above) to 29 percent using the most inclusive possible definition of subsidy takeup, which includes categorizing Medicare HMO enrollees with missing subsidy data as having applied for the subsidy.

Table 7 shows coefficients and standard errors from seven different linear probability models with the seven different Part D takeup variables as outcomes. Even though the different takeup have very different means, they have very similar patterns of response to covariates. So, for example, every measure of takeup shows that individuals with more conditions for which they take prescribed medicines are more likely to take up Part D. Individuals in worse self-reported health are also consistently more likely to take up Part D, although this result is not significant in all specifications. Individuals with better memory scores are consistently more likely to sign up for Part D. Education and demographic characteristics like race and marital status are either insignificant or have inconsistent effects across the different definitions of takeup. There is not much of an income or asset gradient in takeup. ${ }^{8}$ Thus, it appears that Part D takeup was driven mostly by demand for prescription drugs, although there is also evidence that individuals with

\footnotetext{
${ }^{8}$ In results not reported here, we estimated regression which break up all of the continuous variables into sets of dummies (for example self-reported health becomes a set of four dummies instead of a linear variable with values 1-5). This does reveal some nonlinearities in the effect of covariates, but overall the results are qualitatively similar to the ones reported here.
} 
better cognitive functioning (memory) were more likely to sign up. We plan to investigate this result further in the future using additional detailed data from the HRS on other dimensions of cognition, such as numeracy.

Table 8 presents analogous results for nine separate regressions with the different definitions of subsidy takeup as dependent variables. Individuals in worse self-reported health are more likely to apply for the subsidy; the effect of number of prescriptions is small and insignificant in the specifications that do not include Medicaid recipients among those "taking up" the subsidy but is significant and positive in the specifications that do. Older respondents are less likely to sign up for the subsidy, consistent with the results of Haider et al. (2003) for Food Stamps. Individuals with more education or higher memory scores are less likely to apply for the subsidy, in contrast to a positive effect of memory scores on Part D takeup noted above; the effect of memory score on subsidy takeup is inconsistent across specifications, however. As one would expect, more income or assets means individuals are less likely to apply for the subsidy. The effect of demographics (race and except in specifications that include Medicaid recipients among those who take up in which case black, other nonwhite and Hispanic all have big effects. Why do people say they didn't sign up?

Respondents' own stated reasons for not signing up for Part D or the subsidy may be at least as illuminating as the multivariate regression results. Table 9 tabulates those responses for individuals with privately purchased coverage and no coverage in 2006. Options 1-6 in table 9 were the multiple choice responses to the HRS survey question about why respondents did not enroll in Part D while responses 7A through 7D are based on text responses entered by interviewers when the respondent chose "other" from the multiple choice menu. An undergraduate research assistant categorized these text responses into the categories shown between the dashed lines in Table 9. The entries for these categories are sample sizes in each cell rather than cell fractions to emphasize the fact that there are very few responses in any one of these categories.

Table 9 shows that as you might expect, about two-thirds of all respondents with privately purchased coverage in 2006 report that they did not sign up for Part D because they already have coverage. Very few (2.3 percent) chose the response “I didn’t know it was available;" a few (6.2 percent) didn't sign up because they do not use any 
prescription drugs. The detailed analysis of the text responses for respondents with privately purchased coverage offers little evidence to support the view that people did not sign up because they were unaware of the program or confused.

Table 9 also shows responses to “why didn't you sign up?” for respondents whom we classified as having no prescription drug coverage. Eleven percent of these respondents report that they did not sign up for Part D because they already had good coverage, raising concern about measurement error in our drug coverage variable. Very few uninsured respondents say they did not know about the plan (1.4 percent) or heard about it too late (1.9 percent). A significant fraction (12.9 percent) report not having made a decision yet, which may reflect the fact that enrollment in Part D was open through May 15, 2006 and HRS interviews took place throughout 2006. Again, there is very little evidence to support the view that confusion or lack of information prevented uninsured respondents from signing up for Part D coverage.

There is more evidence that confusion and, especially, lack of information help explain why respondents did not apply for the subsidy. Table 10 presents a tabulation of respondent reasons why they did not sign up; as in Table 9, options 1 through 6 were presented to respondents as a menu of reasons for not signing up, while options 7A through 7F were based on text responses recorded by interviewers and analyzed by an undergraduate research assistant. We report these responses for those with Medicare HMO coverage and Part D coverage, both overall and only for those whom we classify as subsidy-eligible. A quarter of respondents overall and 36 percent of subsidy-eligible respondents report that they did not apply for the subsidy because they did not know about it. Fully 41 percent of subsidy-eligible respondents in stand-alone Part D plans report not having known about the subsidy.

How difficult was the decision?

The Part D plan was introduced to apparently widespread confusion and predictions that the elderly would be unable to make good decisions given such complex choices. In spite of this expectation, only about one in six respondents reports that the decision was "very" or "somewhat” difficult (Table 11). The remainder reported that it was not very difficult or not at all difficult, or that they did not make the decision themselves (someone 
else chose for them or they were automatically enrolled). ${ }^{9}$-Enrollees in stand-alone Part D plans did have more difficulty than the other groups; 36 percent of them reported a decision that was very or somewhat difficult. But even for this group - and significantly, even for Part D enrollees with very poor memory scores, less than half found the decision difficult.

Moreover, the majority (69 percent) of Part D plan enrollees reported feeling "very confident” or "somewhat confident” about having made the right decision, and 86 percent of them planned to sign up again the following year. Those who did not enroll mostly did not plan to sign up the following year (21.4 percent of those with privately purchased coverage and 34.6 percent of those with no coverage).

\section{Discussion and conclusion}

We emphasize that this research is at a very preliminary stage. Our results suggest that takeup of Part D was indeed very high with fewer than $10 \%$ of seniors left without coverage, and driven primarily by economic considerations - in particular, those with higher use of prescription drugs or worse self-reported health in 2004 were more likely to sign up for Part D, all else equal. Respondents' stated reasons for declining Part D also suggest that people knew what they were doing and that confusion was not a significant factor keeping potential beneficiaries out of Part D. Consistent with other reports about the subsidy program, our analysis of subsidy applications paints a somewhat different picture, although as noted above our analysis is limited somewhat by missing data and by apparent underreporting of subsidy participation. The available data suggest that few respondents applied for the subsidy and that many subsidy-eligible respondents were not aware of the subsidy, in spite of significant outreach efforts by SSA, and despite their participation in Part D.

\footnotetext{
${ }^{9}$ Note that this table treats Medicaid enrollees' responses about difficulty of the enrollment decision at face value even though in theory all of them should have been automatically enrolled in the program. Medicaid respondents were only asked about difficulty/confidence if they did not report having been automatically enrolled.
} 
Table 1

Insurance coverage and sample characteristics in 2004

\begin{tabular}{|c|c|c|c|c|c|c|}
\hline & \multicolumn{5}{|c|}{ Prescription drug insurance coverage in 2004} & \multirow[b]{3}{*}{ Total } \\
\hline & & \\
\hline & Employer & Medicaid & HMO & Purchase & None & \\
\hline Row percent: & 0.345 & 0.074 & 0.119 & 0.232 & 0.230 & 1.000 \\
\hline Sample n & 3,500 & 891 & 1,132 & 2,306 & 2,346 & 10,175 \\
\hline Age (2006) & 73.3 & 75.7 & 75.6 & 76.8 & 76.4 & 75.3 \\
\hline Female & 0.486 & 0.714 & 0.557 & 0.650 & 0.616 & 0.579 \\
\hline Black & 0.061 & 0.229 & 0.062 & 0.087 & 0.069 & 0.081 \\
\hline Other nonwhite race & 0.026 & 0.096 & 0.033 & 0.022 & 0.019 & 0.029 \\
\hline Hispanic & 0.028 & 0.275 & 0.097 & 0.042 & 0.047 & 0.062 \\
\hline \multicolumn{7}{|l|}{ Health in 2004: } \\
\hline Fair/poor health & 0.216 & 0.594 & 0.251 & 0.291 & 0.271 & 0.278 \\
\hline Any conditions with rx? & 0.676 & 0.782 & 0.657 & 0.696 & 0.615 & 0.672 \\
\hline Number of conditions with rx & & & & & & \\
\hline If $>0(\max =5)^{10}$ & 1.5 & 1.9 & 1.5 & 1.6 & 1.4 & 1.6 \\
\hline Mean memory score $(0-20)$ & 9.7 & 7.2 & 9.0 & 8.6 & 8.7 & 9.0 \\
\hline Memory score missing & 0.063 & 0.137 & 0.060 & 0.071 & 0.070 & 0.072 \\
\hline Education $<\mathrm{HS}$ & 0.160 & 0.659 & 0.227 & 0.296 & 0.278 & 0.263777 \\
\hline Education $=\mathrm{HS}$ & 0.357 & 0.249 & 0.376 & 0.369 & 0.381 & 0.359 \\
\hline Some college & 0.206 & 0.061 & 0.206 & 0.175 & 0.189 & 0.184 \\
\hline College+ & 0.277 & 0.031 & 0.191 & 0.159 & 0.153 & 0.193 \\
\hline \multicolumn{7}{|l|}{ Income/assets in 2005: } \\
\hline Subsidy eligible & 0.176 & 0.821 & 0.260 & 0.330 & 0.325 & 0.304 \\
\hline Income too high & 0.304 & 0.142 & 0.337 & 0.273 & 0.273 & 0.282 \\
\hline Assets too high & 0.046 & 0.013 & 0.062 & 0.069 & 0.061 & 0.054 \\
\hline Both too high & 0.475 & 0.024 & 0.341 & 0.327 & 0.341 & 0.360 \\
\hline
\end{tabular}

${ }^{10}$ High blood pressure, diabetes, heart conditions, stroke, psychiatric conditions 
Table 2

Prescription drug coverage in 2004 and 2006

Row percents and cell counts

\begin{tabular}{|c|c|c|c|c|c|c|c|}
\hline \multirow[b]{2}{*}{ Coverage in 2004: } & \multicolumn{6}{|c|}{ Prescription drug insurance coverage in 2006} & \multirow[b]{2}{*}{ Total } \\
\hline & Employer & Medicaid & MedHMO & Part D & Purchase & None & \\
\hline \multirow[t]{2}{*}{ Employer } & 0.685 & 0.009 & 0.080 & 0.109 & 0.098 & 0.019 & 1.000 \\
\hline & {$[2,408]$} & [39] & {$[261]$} & {$[387]$} & [334] & {$[71]$} & {$[3,500]$} \\
\hline \multirow[t]{2}{*}{ Medicaid } & 0.026 & 0.683 & 0.044 & 0.171 & 0.055 & 0.022 & 1.000 \\
\hline & {$[22]$} & [629] & {$[38]$} & {$[139]$} & {$[43]$} & {$[20]$} & {$[891]$} \\
\hline \multirow[t]{2}{*}{ Medicare HMO } & 0.115 & 0.027 & 0.705 & 0.069 & 0.071 & 0.014 & 1.000 \\
\hline & [129] & [38] & [788] & [86] & [74] & [17] & {$[1,132]$} \\
\hline \multirow[t]{2}{*}{ Purchase } & 0.274 & 0.046 & 0.096 & 0.334 & 0.196 & 0.056 & 1.000 \\
\hline & [615] & [138] & [215] & [764] & [441] & [133] & {$[2,306]$} \\
\hline \multirow[t]{2}{*}{ None } & 0.062 & 0.035 & 0.071 & 0.522 & 0.097 & 0.212 & 1.000 \\
\hline & [144] & [101] & [173] & {$[1,215]$} & [226] & [487] & {$[2,346]$} \\
\hline \multirow[t]{2}{*}{ Total } & 0.332 & 0.073 & 0.153 & 0.257 & 0.114 & 0.072 & 1.000 \\
\hline & {$[3,318]$} & [945] & {$[1,475]$} & {$[2,591]$} & {$[1,118]$} & [728] & {$[10,175]$} \\
\hline
\end{tabular}


Table 3

Part D Outcomes by Income/Assets Relative to Eligibility Thresholds for Low-Income Subsidy

\begin{tabular}{|c|c|c|c|c|c|}
\hline & \multicolumn{4}{|c|}{ Resource relative to eligibility } & \multirow[b]{2}{*}{ Total } \\
\hline & Eligible & $\begin{array}{l}\text { Income } \\
\text { too high }\end{array}$ & $\begin{array}{l}\text { Assets } \\
\text { too high }\end{array}$ & $\begin{array}{l}\text { Both } \\
\text { too high }\end{array}$ & \\
\hline Row percent & 0.304 & 0.282 & 0.054 & 0.361 & 1.000 \\
\hline Sample n & 3,302 & 2,923 & 523 & 3,427 & 10,175 \\
\hline \multicolumn{6}{|c|}{ Distribution of 2004 Rx coverage: } \\
\hline Employer & 0.200 & 0.372 & 0.291 & 0.454 & 0.345 \\
\hline Medicaid & 0.199 & 0.037 & 0.018 & 0.005 & 0.074 \\
\hline Medicare HMO & 0.102 & 0.143 & 0.136 & 0.113 & 0.119 \\
\hline Purchase & 0.253 & 0.225 & 0.298 & 0.211 & 0.232 \\
\hline None & 0.246 & 0.223 & 0.257 & 0.217 & 0.230 \\
\hline Total & 1.000 & 1.000 & 1.000 & 1.000 & 1.000 \\
\hline \multicolumn{6}{|c|}{ Distribution of 2006 Rx coverage: } \\
\hline Employer & 0.212 & 0.345 & 0.326 & 0.415 & 0.329 \\
\hline Medicaid & 0.197 & 0.043 & 0.017 & 0.006 & 0.075 \\
\hline Medicare HMO & 0.128 & 0.185 & 0.158 & 0.153 & 0.155 \\
\hline Part D & 0.273 & 0.245 & 0.295 & 0.247 & 0.257 \\
\hline Purchase & 0.117 & 0.112 & 0.121 & 0.111 & 0.114 \\
\hline None & 0.073 & 0.070 & 0.082 & 0.069 & 0.071 \\
\hline Total & 1.000 & 1.000 & 1.000 & 1.000 & 1.000 \\
\hline \multicolumn{6}{|c|}{ Prob(apply for subsidy) } \\
\hline Part D enrollees & 0.134 & 0.094 & 0.100 & 0.019 & 0.081 \\
\hline \multicolumn{6}{|c|}{ Medicare HMO enrollees } \\
\hline Yes & 0.052 & 0.028 & 0.000 & 0.013 & 0.027 \\
\hline No & 0.736 & 0.676 & 0.843 & 0.721 & 0.716 \\
\hline Not asked & 0.212 & 0.296 & 0.157 & 0.266 & 0.257 \\
\hline \multicolumn{6}{|c|}{$\begin{array}{l}\text { Outcome of subsidy application } \\
\text { (PDP/MedHMO enrollees) }\end{array}$} \\
\hline Approved & 0.566 & 0.290 & 0.187 & 0.329 & 0.430 \\
\hline Denied & 0.328 & 0.644 & 0.656 & 0.603 & 0.477 \\
\hline Waiting & 0.107 & 0.067 & 0.157 & 0.068 & 0.094 \\
\hline
\end{tabular}


Table 4

Part D Outcomes by Income/Assets Relative to Eligibility Thresholds for Low-Income Subsidy

\begin{tabular}{lrrrrr}
\hline & \multicolumn{3}{c}{ Resource relative to eligibility } & \\
\cline { 2 - 5 } & & Income & Assets & Both & \\
& Eligible & too high & too high & too high & Total \\
Row percent & 0.304 & 0.282 & 0.054 & 0.361 & 1.000 \\
Sample n & 3,302 & 2,923 & 523 & 3,427 & 10,175 \\
& & & & & \\
Employer & 0.212 & 0.345 & 0.326 & 0.415 & 0.329 \\
Medicaid & 0.197 & 0.043 & 0.017 & 0.006 & 0.075 \\
Medicare HMO: Did not apply for subsidy & 0.094 & 0.125 & 0.133 & 0.110 & 0.111 \\
Medicare HMO: Got subsidy & 0.004 & 0.002 & 0.000 & 0.000 & 0.002 \\
Medicare HMO: Denied subsidy & 0.002 & 0.003 & 0.000 & 0.002 & 0.002 \\
Medicare HMO: Subsidy app. pending & 0.000 & 0.000 & 0.000 & 0.000 & 0.000 \\
Medicare HMO: Don't know subsidy status & 0.027 & 0.055 & 0.025 & 0.041 & 0.040 \\
PDP: Did not apply for subsidy & 0.237 & 0.222 & 0.266 & 0.242 & 0.236 \\
PDP: Got subsidy & 0.020 & 0.007 & 0.006 & 0.002 & 0.009 \\
PDP: Denied subsidy & 0.013 & 0.015 & 0.019 & 0.002 & 0.010 \\
PDP: Subsidy application pending & 0.004 & 0.002 & 0.005 & 0.000 & 0.002 \\
Purchase & 0.117 & 0.112 & 0.121 & 0.111 & 0.114 \\
None & 0.073 & 0.070 & 0.082 & 0.069 & 0.071 \\
Total & 1.000 & 1.000 & 1.000 & 1.000 & 1.000 \\
\hline
\end{tabular}


Table 5

Different definitions of takeup

Definition of takeup/numerator

Universe/denominator

Denom. $\mathrm{n}$

\section{Part D}

D1 PDP in $2006 \quad$ PDP, privately purchased or no

coverage in 2006

4,437

D2 PDP or MedHMO in 2006

PDP, privately purchased coverage, MedHMO or no coverage in 2006

D3 PDP, MedHMO or Medicaid in 2006

PDP, privately purchased coverage, MedHMO, Medicaid or no coverage in 2006

D4 PDP in 2006 Privately purchased or no coverage in 2004

D5 PDP or MedHMO in 2006

Privately purchased coverage, MedHMO or no coverage in 2004

D6 PDP, MedHMO or Medicaid in 2006 Privately purchased coverage, MedHMO, Medicaid or no coverage in 2004

D7 “Did you sign up for Part D”=yes

All respondents 65+ with Medicare in 2006

\section{“Extra Help" subsidy}

X1 PDP 06 with subsidy=yes

PDP 06

X2 PDP 06 with subsidy=yes

PDP 06 + MedHMO 06,

+ MedHMO 06 with subsidy=yes excluding those missing subsidy data

PDP 06 with subsidy=yes

PDP 06 + MedHMO 06,

+ MedHMO 06 with subsidy=yes

including those missing subsidy data

X3

X4 PDP 06 with subsidy=yes

PDP 06 + MedHMO 06,

+ MedHMO 06 with subsidy=yes

including those missing subsidy data

+ MedHMO06 with subsidy=missing

X5 PDP 06 with subsidy=yes PDP $06+$ Medicaid 06

+ Medicaid 06

X6 PDP 06 with subsidy=yes

PDP 06 + MedHMO 06 + Medicaid 06

+ MedHMO 06 with subsidy=yes

excluding those missing subsidy data

+ Medicaid 06

X7 PDP 06 with subsidy=yes
+ MedHMO 06 with subsidy

+ MedHMO 06 with subsidy=yes

+ Medicaid 06

PDP 06 + MedHMO 06 + Medicaid 06

including those missing subsidy data

PDP 06 + MedHMO 06 + Medicaid 06

X8 PDP 06 with subsidy=yes

including those missing subsidy data

+ MedHMO 06 with subsidy=yes

+ MedHMO 06 with subsidy=missing

+ Medicaid 06 
Table 6

Average takeup using different definitions of takeup by income/assets relative to subsidy eligibility threshold

Row percent

Sample $n$
Resource relative to eligibility

\begin{tabular}{rrrcr}
\cline { 2 - 4 } Eligible & $\begin{array}{c}\text { Income } \\
\text { too high }\end{array}$ & $\begin{array}{r}\text { Assets } \\
\text { too high }\end{array}$ & $\begin{array}{c}\text { Both too } \\
\text { high }\end{array}$ & Total \\
0.304 & 0.282 & 0.054 & 0.361 & 1.000 \\
3,302 & 2,923 & 523 & 3,427 & 10,175
\end{tabular}

Definition of Part D takeup

D1

D2

D3

D4

D5

D6

D7

Definition of subsidy takeup

$\mathrm{X} 1$

$\mathrm{X} 2$

$\mathrm{X} 3$

$\mathrm{X} 4$

$\mathrm{X} 5$

X6

$\mathrm{X} 7$

$\mathrm{X} 8$

$\mathrm{X} 9$ $\begin{array}{lllll}0.590 & 0.575 & 0.592 & 0.579 & 0.582\end{array}$

$\begin{array}{lllll}0.679 & 0.703 & 0.691 & 0.690 & 0.691\end{array}$

$\begin{array}{lllll}0.759 & 0.723 & 0.699 & 0.693 & 0.725\end{array}$

$\begin{array}{lllll}0.417 & 0.424 & 0.436 & 0.442 & 0.429\end{array}$

$\begin{array}{lllll}0.541 & 0.583 & 0.591 & 0.576 & 0.568\end{array}$

$\begin{array}{lllll}0.655 & 0.607 & 0.602 & 0.580 & 0.616\end{array}$

$\begin{array}{lllll}0.497 & 0.384 & 0.431 & 0.355 & 0.411\end{array}$

$\begin{array}{lllll}0.134 & 0.094 & 0.100 & 0.019 & 0.081\end{array}$

$\begin{array}{lllll}0.116 & 0.075 & 0.069 & 0.018 & 0.067\end{array}$

$\begin{array}{lllll}0.107 & 0.065 & 0.065 & 0.016 & 0.060\end{array}$

$\begin{array}{lllll}0.185 & 0.194 & 0.120 & 0.119 & 0.161\end{array}$

$\begin{array}{lllll}0.500 & 0.228 & 0.149 & 0.043 & 0.290\end{array}$

$\begin{array}{lllll}0.423 & 0.170 & 0.105 & 0.035 & 0.224\end{array}$

$\begin{array}{lllll}0.401 & 0.150 & 0.099 & 0.031 & 0.205\end{array}$

$\begin{array}{lllll}0.453 & 0.266 & 0.152 & 0.133 & 0.290\end{array}$

$\begin{array}{lllll}0.078 & 0.047 & 0.043 & 0.012 & 0.044\end{array}$


Table 7

Regression models: Takeup of Part D

\begin{tabular}{|c|c|c|c|c|c|c|c|}
\hline \multirow{3}{*}{ No. of conditions with rx } & \multicolumn{7}{|c|}{ Definition of Part D takeup used as dependent variable (see Table 5) } \\
\hline & 1 & 2 & 3 & 4 & 5 & 6 & 7 \\
\hline & $\begin{array}{c}0.046 \\
{[0.009]}\end{array}$ & $\begin{array}{c}0.042 \\
{[0.007]}\end{array}$ & $\begin{array}{c}0.04 \\
{[0.006]}\end{array}$ & $\begin{array}{c}0.02 \\
{[0.009]}\end{array}$ & $\begin{array}{c}0.024 \\
{[0.008]}\end{array}$ & $\begin{array}{c}0.033 \\
{[0.007]}\end{array}$ & $\begin{array}{c}0.016 \\
{[0.006]}\end{array}$ \\
\hline $\begin{array}{l}\text { Self-reported health } \\
\text { (1=Ex, 5=Poor) }\end{array}$ & $\begin{array}{c}0.015 \\
{[0.008]}\end{array}$ & $\begin{array}{c}0.007 \\
{[0.006]}\end{array}$ & $\begin{array}{c}0.012 \\
{[0.006]}\end{array}$ & $\begin{array}{c}0.017 \\
{[0.008]}\end{array}$ & $\begin{array}{c}0.008 \\
{[0.007]}\end{array}$ & $\begin{array}{c}0.013 \\
{[0.006]}\end{array}$ & $\begin{array}{c}0.027 \\
{[0.005]}\end{array}$ \\
\hline Memory score & $\begin{array}{c}0.004 \\
{[0.003]}\end{array}$ & $\begin{array}{c}0.005 \\
{[0.002]}\end{array}$ & $\begin{array}{c}0.004 \\
{[0.002]}\end{array}$ & $\begin{array}{c}0.002 \\
{[0.003]}\end{array}$ & $\begin{array}{c}0.004 \\
{[0.002]}\end{array}$ & $\begin{array}{c}0.003 \\
{[0.002]}\end{array}$ & $\begin{array}{l}-0.001 \\
{[0.002]}\end{array}$ \\
\hline Memory score missing & $\begin{array}{c}0.032 \\
{[0.035]}\end{array}$ & $\begin{array}{c}0.019 \\
{[0.029]}\end{array}$ & $\begin{array}{c}0.028 \\
{[0.025]}\end{array}$ & $\begin{array}{l}-0.003 \\
{[0.035]}\end{array}$ & $\begin{array}{c}0.011 \\
{[0.032]}\end{array}$ & $\begin{array}{c}0.029 \\
{[0.028]}\end{array}$ & $\begin{array}{c}0.003 \\
{[0.023]}\end{array}$ \\
\hline Age & $\begin{array}{l}-0.006 \\
{[0.001]}\end{array}$ & $\begin{array}{l}-0.005 \\
{[0.001]}\end{array}$ & $\begin{array}{c}-0.005 \\
{[0.001]}\end{array}$ & & & & $\begin{array}{l}-0.003 \\
{[0.001]}\end{array}$ \\
\hline Married & $\begin{array}{c}0.02 \\
{[0.017]}\end{array}$ & $\begin{array}{c}0.032 \\
{[0.014]}\end{array}$ & $\begin{array}{c}0.009 \\
{[0.012]}\end{array}$ & $\begin{array}{c}0.068 \\
{[0.017]}\end{array}$ & $\begin{array}{c}0.073 \\
{[0.015]}\end{array}$ & $\begin{array}{c}0.040 \\
{[0.014]}\end{array}$ & $\begin{array}{l}-0.025 \\
{[0.011]}\end{array}$ \\
\hline Black & & $\begin{array}{c}-0.023 \\
{[0.046]}\end{array}$ & $\begin{array}{c}-0.021 \\
{[0.036]}\end{array}$ & $\begin{array}{l}-0.060 \\
{[0.060]}\end{array}$ & & $\begin{array}{c}-0.032 \\
{[0.041]}\end{array}$ & $\begin{array}{l}-0.090 \\
{[0.034]}\end{array}$ \\
\hline Nonwhite & $\begin{array}{l}-0.001 \\
{[0.052]}\end{array}$ & $\begin{array}{c}0.002 \\
{[0.040]}\end{array}$ & $\begin{array}{c}0.039 \\
{[0.031]}\end{array}$ & $\begin{array}{c}0.015 \\
{[0.054]}\end{array}$ & $\begin{array}{c}0.005 \\
{[0.045]}\end{array}$ & $\begin{array}{c}0.051 \\
{[0.036]}\end{array}$ & $\begin{array}{c}0.082 \\
{[0.030]}\end{array}$ \\
\hline Hispanic & & $\begin{array}{c}0.099 \\
{[0.028]}\end{array}$ & $\begin{array}{c}0.137 \\
{[0.022]}\end{array}$ & $\begin{array}{l}-0.101 \\
{[0.038]}\end{array}$ & $\begin{array}{c}0.042 \\
{[0.030]}\end{array}$ & $\begin{array}{c}0.124 \\
{[0.024]}\end{array}$ & $\begin{array}{c}0.08 \\
{[0.022]}\end{array}$ \\
\hline Female & $\begin{array}{c}0.065 \\
{[0.017]}\end{array}$ & $\begin{array}{c}0.027 \\
{[0.013]}\end{array}$ & $\begin{array}{c}0.028 \\
{[0.012]}\end{array}$ & $\begin{array}{c}0.090 \\
{[0.017]}\end{array}$ & $\begin{array}{c}0.054 \\
{[0.015]}\end{array}$ & $\begin{array}{c}0.055 \\
{[0.014]}\end{array}$ & $\begin{array}{c}0.093 \\
{[0.011]}\end{array}$ \\
\hline Education=HS & $\begin{array}{l}-0.015 \\
{[0.020]}\end{array}$ & $\begin{array}{c}0.007 \\
{[0.016]}\end{array}$ & $\begin{array}{c}-0.018 \\
{[0.014]}\end{array}$ & $\begin{array}{c}0.000 \\
{[0.019]}\end{array}$ & $\begin{array}{c}0.025 \\
{[0.017]}\end{array}$ & $\begin{array}{c}-0.011 \\
{[0.016]}\end{array}$ & $\begin{array}{l}-0.067 \\
{[0.013]}\end{array}$ \\
\hline Education=Some college & $\begin{array}{c}-0.005 \\
{[0.024]}\end{array}$ & $\begin{array}{c}0.018 \\
{[0.019]}\end{array}$ & $\begin{array}{c}-0.008 \\
{[0.018]}\end{array}$ & $\begin{array}{c}0.009 \\
{[0.024]}\end{array}$ & $\begin{array}{c}0.042 \\
{[0.021]}\end{array}$ & $\begin{array}{c}0.000 \\
{[0.019]}\end{array}$ & $\begin{array}{c}-0.068 \\
{[0.016]}\end{array}$ \\
\hline Education=College & $\begin{array}{c}0.005 \\
{[0.025]}\end{array}$ & $\begin{array}{c}0.016 \\
{[0.021]}\end{array}$ & $\begin{array}{c}-0.005 \\
{[0.019]}\end{array}$ & $\begin{array}{c}0.013 \\
{[0.025]}\end{array}$ & $\begin{array}{c}0.027 \\
{[0.023]}\end{array}$ & $\begin{array}{c}-0.006 \\
{[0.021]}\end{array}$ & $\begin{array}{c}-0.062 \\
{[0.016]}\end{array}$ \\
\hline Income decile & $\begin{array}{c}-0.003 \\
{[0.003]}\end{array}$ & $\begin{array}{c}-0.001 \\
{[0.002]}\end{array}$ & $\begin{array}{c}-0.004 \\
{[0.002]}\end{array}$ & $\begin{array}{c}0.001 \\
{[0.003]}\end{array}$ & $\begin{array}{c}-0.001 \\
{[0.002]}\end{array}$ & $\begin{array}{c}-0.006 \\
{[0.002]}\end{array}$ & $\begin{array}{l}-0.010 \\
{[0.002]}\end{array}$ \\
\hline Asset decile & $\begin{array}{c}0.004 \\
{[0.003]}\end{array}$ & $\begin{array}{c}0.002 \\
{[0.003]}\end{array}$ & $\begin{array}{c}0.000 \\
{[0.002]}\end{array}$ & $\begin{array}{c}0.003 \\
{[0.003]}\end{array}$ & $\begin{array}{c}0.002 \\
{[0.003]}\end{array}$ & $\begin{array}{c}-0.001 \\
{[0.003]}\end{array}$ & $\begin{array}{c}0.001 \\
{[0.002]}\end{array}$ \\
\hline Constant & $\begin{array}{c}0.854 \\
{[0.105]}\end{array}$ & $\begin{array}{c}0.952 \\
{[0.086]}\end{array}$ & $\begin{array}{c}1.018 \\
{[0.076]}\end{array}$ & $\begin{array}{c}0.425 \\
{[0.104]}\end{array}$ & $\begin{array}{c}0.694 \\
{[0.094]}\end{array}$ & $\begin{array}{c}0.875 \\
{[0.085]}\end{array}$ & $\begin{array}{c}0.592 \\
{[0.069]}\end{array}$ \\
\hline Observations & 4,437 & 5,912 & 6,857 & 4,652 & 5,784 & 6,675 & 10,175 \\
\hline
\end{tabular}

Standard errors in brackets 
Table 8

Regression model: Applications for subsidy

Definition of subsidy takeup used as dependent variable (see Table 5)

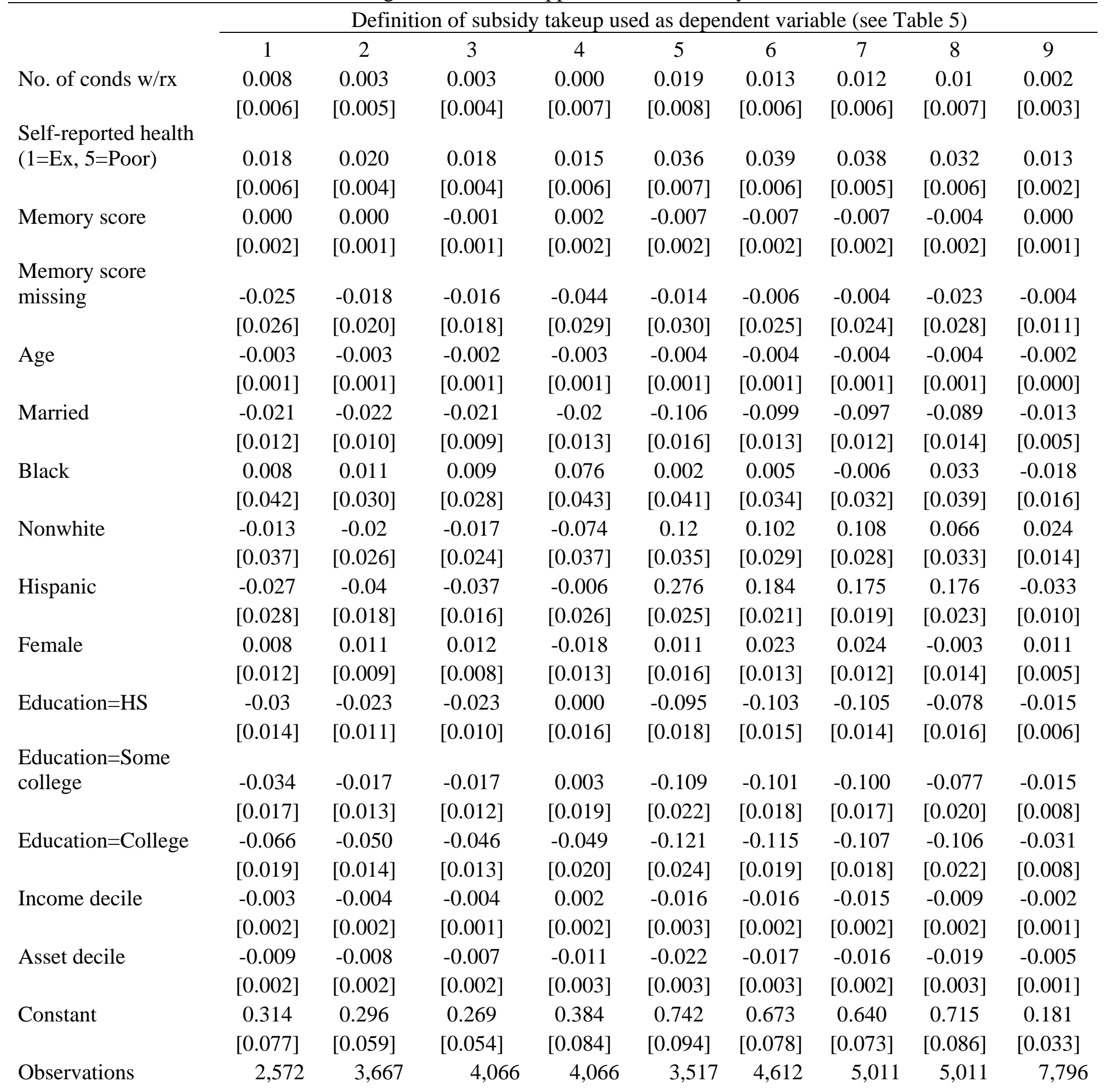

Standard errors in Brackets. 
Table 9

Stated reasons for not enrolling in Part D

\begin{tabular}{|c|c|c|c|}
\hline & \multicolumn{2}{|c|}{ Rx coverage in 2006} & \multirow[b]{2}{*}{ Total } \\
\hline & Purchase & None & \\
\hline Sample n & 1,118 & 728 & 1,846 \\
\hline (1) Already have good coverage & 0.617 & 0.113 & 0.423 \\
\hline (2) Didn't know it was available & 0.023 & 0.014 & 0.019 \\
\hline (3) Heard about it too late & 0.008 & 0.019 & 0.012 \\
\hline (4) Medicare plan too expensive & 0.029 & 0.107 & 0.059 \\
\hline (5) Medicare plan too restrictive & 0.002 & 0.005 & 0.003 \\
\hline (6) Haven't made a decision yet & 0.032 & 0.129 & 0.069 \\
\hline (7A) Other: no additional info & 0.011 & 0.036 & 0.021 \\
\hline (7B) Other: text = no meds & 0.062 & 0.217 & 0.122 \\
\hline (7C) Other: text = other coverage & 0.045 & 0.038 & 0.042 \\
\hline (7D) Other: text = other & 0.109 & 0.273 & 0.172 \\
\hline Advised not to & 3 & 1 & 4 \\
\hline Can't afford & 1 & 3 & 4 \\
\hline Confusion & 37 & 55 & 92 \\
\hline Enrolled/ing & 3 & 5 & 8 \\
\hline Family didn't allow & 1 & 3 & 4 \\
\hline Foreign Meds & 0 & 5 & 5 \\
\hline Forgot & 2 & 5 & 7 \\
\hline Free meds & 2 & 5 & 7 \\
\hline Future & 5 & 2 & 7 \\
\hline Government & 6 & 4 & 10 \\
\hline Ineligible & 15 & 16 & 31 \\
\hline Misc & 7 & 7 & 14 \\
\hline No Benefit & 4 & 10 & 14 \\
\hline No Info received & 2 & 3 & 5 \\
\hline No need & 10 & 12 & 22 \\
\hline No reason & 8 & 14 & 22 \\
\hline No time & 1 & 2 & 3 \\
\hline Prefers Natural Herbs & 0 & 4 & 4 \\
\hline Rip off & 7 & 18 & 25 \\
\hline Skeptical & 7 & 17 & 24 \\
\hline Still deciding & 3 & 6 & 9 \\
\hline Total & 124 & 197 & 321 \\
\hline (8A) Why not enroll = DK & 0.013 & 0.010 & 0.012 \\
\hline (8B) Why not enroll = missing & 0.000 & 0.002 & 0.001 \\
\hline (8C) Missing data on Part D enrollment & 0.050 & 0.038 & 0.046 \\
\hline Total & 1.000 & 1.000 & 1.000 \\
\hline
\end{tabular}


Table 10

Stated reasons for not applying for subsidy

\begin{tabular}{|c|c|c|c|c|c|c|}
\hline & \multicolumn{3}{|c|}{ All income/asset levels } & \multicolumn{3}{|c|}{ Subsidy-eligible only } \\
\hline & MedHMO & Part D & Total & MedHMO & Part D & Total \\
\hline Sample n & 1,475 & 2,591 & 4,066 & 384 & 875 & 1,259 \\
\hline (1) Too much income & 0.183 & 0.325 & 0.269 & 0.114 & 0.173 & 0.153 \\
\hline (2) Too much wealth & 0.031 & 0.045 & 0.040 & 0.018 & 0.030 & 0.026 \\
\hline (3) Too much resources & 0.024 & 0.045 & 0.037 & 0.014 & 0.026 & 0.022 \\
\hline (4) Didn't know about it & 0.189 & 0.291 & 0.252 & 0.260 & 0.414 & 0.362 \\
\hline (5) Too much bother/confusing & 0.006 & 0.018 & 0.013 & 0.010 & 0.033 & 0.025 \\
\hline (6) Haven't gotten around to it & 0.005 & 0.016 & 0.012 & 0.013 & 0.030 & 0.025 \\
\hline (7A) Other: no additional info & 0.028 & 0.015 & 0.020 & 0.031 & 0.008 & 0.016 \\
\hline (7B) Other: text $=$ no meds & 0.035 & 0.041 & 0.039 & 0.042 & 0.037 & 0.039 \\
\hline (7C) Other: text = other coverage & 0.105 & 0.039 & 0.065 & 0.116 & 0.050 & 0.072 \\
\hline (7D) Other: text $=$ no need for it & 0.059 & 0.066 & 0.063 & 0.067 & 0.067 & 0.067 \\
\hline (7E) Other: text = OK w/o it & 0.021 & 0.020 & 0.020 & 0.029 & 0.017 & 0.021 \\
\hline (7F) Other: text = other & 0.036 & 0.048 & 0.044 & 0.033 & 0.071 & 0.058 \\
\hline Advised not to & 1 & 1 & 2 & 0 & 0 & 0 \\
\hline Believe Ineligible & 9 & 27 & 36 & 4 & 12 & 16 \\
\hline Confusion & 8 & 21 & 29 & 2 & 8 & 10 \\
\hline Didn't make decision & 2 & 6 & 8 & 1 & 1 & 2 \\
\hline Didn't want to & 2 & 1 & 3 & 1 & 0 & 1 \\
\hline Dislike program & 0 & 5 & 5 & 0 & 2 & 2 \\
\hline Enrolled & 3 & 6 & 9 & 0 & 3 & 3 \\
\hline Foreign meds & 0 & 1 & 1 & 0 & 0 & 0 \\
\hline Forgot & 0 & 2 & 2 & 0 & 1 & 1 \\
\hline Free meds & 4 & 2 & 6 & 2 & 1 & 3 \\
\hline Future & 1 & 2 & 3 & 0 & 2 & 2 \\
\hline Government & 1 & 1 & 2 & 0 & 0 & 0 \\
\hline Misc. & 2 & 10 & 12 & 0 & 7 & 7 \\
\hline No Social Security & 2 & 0 & 2 & 0 & 0 & 0 \\
\hline No reason & 10 & 28 & 38 & 4 & 15 & 19 \\
\hline En Español & 9 & 6 & 15 & 2 & 4 & 6 \\
\hline Total & 54 & 119 & 173 & 16 & 56 & 72 \\
\hline (8A) Missing all subsidy data & 0.263 & 0.000 & 0.103 & 0.220 & 0.001 & 0.076 \\
\hline (8B) Don’t know & 0.015 & 0.028 & 0.023 & 0.028 & 0.038 & 0.034 \\
\hline (8C) Refused & 0.001 & 0.001 & 0.001 & 0.005 & 0.005 & 0.005 \\
\hline Total & 1.000 & 1.000 & 1.000 & 1.000 & 1.000 & 1.000 \\
\hline
\end{tabular}


Table 11

Self-reported difficulty making decision

\begin{tabular}{|c|c|c|c|c|c|c|c|}
\hline & \multicolumn{6}{|c|}{ Type of Rx coverage in 2006} & \multirow{3}{*}{ Total } \\
\hline & Employer & Medicaid & MedHMO & Part D & Purchase & None & \\
\hline \multicolumn{7}{|c|}{ How difficult was decision? } & \\
\hline Very & 0.028 & 0.069 & 0.041 & 0.154 & 0.044 & 0.054 & 0.069 \\
\hline Somewhat & 0.051 & 0.055 & 0.039 & 0.217 & 0.072 & 0.071 & 0.096 \\
\hline Not very & 0.097 & 0.088 & 0.075 & 0.164 & 0.119 & 0.137 & 0.116 \\
\hline Not at all & 0.693 & 0.213 & 0.401 & 0.215 & 0.548 & 0.453 & 0.455 \\
\hline Didn't decide myself & 0.026 & 0.064 & 0.023 & 0.056 & 0.038 & 0.035 & 0.038 \\
\hline Auto-enrolled & 0.031 & 0.393 & 0.348 & 0.142 & 0.000 & 0.000 & 0.130 \\
\hline DK & 0.003 & 0.005 & 0.006 & 0.003 & 0.027 & 0.019 & 0.007 \\
\hline $\mathrm{RF}$ & 0.000 & 0.000 & 0.000 & 0.000 & 0.000 & 0.000 & 0.000 \\
\hline Missing & 0.070 & 0.113 & 0.067 & 0.049 & 0.152 & 0.230 & 0.089 \\
\hline Total & 1.000 & 1.000 & 1.000 & 1.000 & 1.000 & 1.000 & 1.000 \\
\hline \multicolumn{8}{|c|}{ Fraction reporting very or somewhat difficult decision, by insurance coverage and memory score } \\
\hline \multicolumn{8}{|c|}{ Memory score: } \\
\hline $0-4$ & 0.117 & 0.139 & 0.085 & 0.327 & 0.164 & 0.119 & 0.182 \\
\hline $5-6$ & 0.093 & 0.172 & 0.089 & 0.342 & 0.147 & 0.150 & 0.184 \\
\hline 7 & 0.081 & 0.139 & 0.050 & 0.359 & 0.096 & 0.187 & 0.168 \\
\hline 8 & 0.115 & 0.149 & 0.129 & 0.415 & 0.132 & 0.153 & 0.195 \\
\hline 9 & 0.104 & 0.136 & 0.073 & 0.456 & 0.118 & 0.131 & 0.200 \\
\hline 10 & 0.051 & 0.165 & 0.122 & 0.400 & 0.112 & 0.267 & 0.174 \\
\hline 11 & 0.079 & 0.136 & 0.078 & 0.432 & 0.103 & 0.148 & 0.183 \\
\hline $12-13$ & 0.071 & 0.120 & 0.079 & 0.431 & 0.185 & 0.175 & 0.188 \\
\hline $14+$ & 0.085 & 0.032 & 0.073 & 0.414 & 0.196 & 0.198 & 0.189 \\
\hline Total & 0.086 & 0.145 & 0.088 & 0.397 & 0.141 & 0.169 & 0.185 \\
\hline
\end{tabular}

Note that Medicaid enrollees' responses about difficulty are taken at face value even though they were, in fact, all automatically enrolled. 
Table 12

Confidence in decision and intention to sign up next year

\begin{tabular}{|c|c|c|c|c|c|c|c|}
\hline & \multicolumn{6}{|c|}{ Type of Rx coverage in 2006} & \multirow[b]{2}{*}{ Total } \\
\hline \multicolumn{7}{|c|}{ How confident are you that you made the right decision? } & \\
\hline Very & 0.752 & 0.286 & 0.436 & 0.404 & 0.582 & 0.432 & 0.535 \\
\hline Somewhat & 0.110 & 0.137 & 0.104 & 0.290 & 0.171 & 0.197 & 0.171 \\
\hline Not very & 0.013 & 0.040 & 0.022 & 0.053 & 0.035 & 0.039 & 0.031 \\
\hline Not at all & 0.013 & 0.018 & 0.010 & 0.037 & 0.023 & 0.046 & 0.023 \\
\hline Auto-enrolled & 0.031 & 0.393 & 0.348 & 0.142 & 0.000 & 0.000 & 0.130 \\
\hline $\mathrm{DK}$ & 0.007 & 0.013 & 0.010 & 0.025 & 0.031 & 0.040 & 0.018 \\
\hline $\mathrm{RF}$ & 0.001 & 0.000 & 0.000 & 0.000 & 0.001 & 0.001 & 0.000 \\
\hline Missing & 0.073 & 0.113 & 0.070 & 0.049 & 0.158 & 0.245 & 0.092 \\
\hline Total & 1.000 & 1.000 & 1.000 & 1.000 & 1.000 & 1.000 & 1.000 \\
\hline \multicolumn{8}{|c|}{ How likely is it that you will sign up for Medicare prescription drug coverage next year? } \\
\hline Very & 0.078 & 0.515 & 0.330 & 0.703 & 0.082 & 0.170 & 0.318 \\
\hline Somewhat & 0.066 & 0.148 & 0.099 & 0.159 & 0.133 & 0.176 & 0.117 \\
\hline Not very & 0.167 & 0.080 & 0.148 & 0.036 & 0.241 & 0.225 & 0.136 \\
\hline Not at all & 0.656 & 0.152 & 0.371 & 0.044 & 0.452 & 0.330 & 0.370 \\
\hline Missing & 0.033 & 0.106 & 0.053 & 0.058 & 0.092 & 0.099 & 0.059 \\
\hline Total & 1.000 & 1.000 & 1.000 & 1.000 & 1.000 & 1.000 & 1.000 \\
\hline
\end{tabular}

Note that Medicaid enrollees' responses about confidence are taken at face value even though they were, in fact, all automatically enrolled. 
Appendix Table 1

Patterns of response to "Did you sign up for part d" and "Did you apply for the subsidy"

By Rx coverage status in 2006

"Yes" to "Did you sign up for Part D?" Of those who said yes to Part D:

"I was automatically enrolled"

"I applied for the subsidy"

Responses to subsidy question, including missing:

Yes

No

Missing
Assigned $2006 \mathrm{Rx}$ coverage status

$\begin{array}{rrrrrrr}\text { Employer } & \text { Medicaid } & \text { MedHMO } & \text { Part D } & \text { Purchase } & \text { None } & \text { Total } \\ 0.079 & 0.705 & 0.483 & 1.000 & 0.000 & 0.000 & 0.416 \\ & & & & & & \\ 0.410 & 0.538 & 0.697 & 0.146 & - & - & 0.317 \\ 0.031 & 0.094 & 0.055 & 0.085 & - & - & 0.078 \\ & & & & & & \\ 0.007 & 0.068 & 0.028 & 0.084 & 0.012 & 0.006 & 0.036 \\ 0.687 & 0.770 & 0.715 & 0.909 & 0.566 & 0.529 & 0.730 \\ 0.306 & 0.162 & 0.258 & 0.007 & 0.422 & 0.466 & 0.234\end{array}$




\section{References}

Blundell, Richard, Vanessa Fry, and Ian Walker. 1988. "Modelling the Take-up of Means-Tested Benefits: The Case of Housing Benefits in the UK," The Economic Journal 98(390):58-74.

CBO 2004. Congressional Budget Office, “A Detailed Description of CBO’s Cost Estimate for the Medicare Prescription Drug Benefit” July, 2004.

Currie, Janet. 2004. “The Take-Up of Social Benefits” NBER Working Paper \#10488, May, 2004.

Elder, Todd and Elizabeth Powers. 2004. "SSI for the Aged and the Problem of 'TakeUp’,”. Michigan Retirment Research Center Working Paper 2004-076.

Elder, Todd and Elizabeth Powers. 2006. "Public Health Insurance and SSI Program Participation Among the Aged," Michigan Retirment Research Center Working Paper 2006-117.

GAO-07-858T. 2007. "Medicare Part D Low-Income Subsidy: Progress Made in Approving Applications, but Ability to Identify Remaining Individuals Is Limited,” Testimony to the Senate Committee on Finance , Statement of Barbara Bovbjerg, May 8, 2007.

Haider, Steven J., Alison Jacknowitz and Robert F. Schoeni. 2003. "Food Stamps and the Elderly: Why Is Participation So Low?” Journal of Human Resources 38:1080-1111.

McGarry, Kathleen. 1996. "Factors Determining Participation of the Elderly in Supplemental Security Income,” Journal of Human Resources 31(2): 331-358.

Moffitt, Robert. 1983. “An Economic Model of Welfare Stigma,” American Economic Review 73(5):1023-1035

Pezzin. Liliana E. and Judith D. Kasper. 2002. “Medicaid Enrollment among Elderly Medicare Beneficiaries: Individual Determinants, Effects of State Policy, and Impact on Service Use,” Health Services Research 37(4): 827-847. 